\title{
Kumaravadivelu, B. (2008) Cultural Globalization and Language Education. Estados Unidos: Yale University.
}

Jorge Salinas Hurtado

CEPE-TaxCO

Uno de los retos más grandes al que se enfrentan los maestros de español como lengua extranjera es el manejo de un grupo de alumnos que provienen de distintas culturas con un bagaje de valores y expectativas diferentes. Sin embargo, estos estudiantes además de querer aprender los aspectos lingüísticos del nuevo idioma, también desean entender la forma de pensar y de actuar de sus hablantes, saber qué respuestas son apropiadas y cuáles no. Kumaravadivelu ofrece en su libro ideas para incorporar estos aspectos en las clases de lenguas con el objetivo de lograr un mejor acercamiento entre las culturas en un mundo en que los efectos de la globalización son cada vez más inmediatos en el salón de clases.

Aunque cada vez es más evidente la relevancia de los contenidos culturales, el autor nos lleva a reflexionar sobre qué tanto es deseable que los alumnos se asimilen a la cultura meta. Ofrece un análisis detallado acerca de cómo los conceptos: asimilación, pluralismo cultural e hibridez cultural impactan en la enseñanza de lenguas extranjeras.

Un aspecto que considero muy valioso es que la perspectiva del autor proviene de su propia experiencia como maestro que emigró de su natal India, para enseñar en universidades en Estados Unidos. Esto le da un aporte original, ya que la mayoría de los estudios de comunicación intercultural se han hecho siempre desde un punto de vista occidental, bastante eurocentrista.

Al hablar sobre la cultura y sus complejidades, retoma la hipótesis de Sapir-Whorf acerca de la cultura y la lengua para resaltar la importancia de esta conexión. Aborda el papel que actualmente se le da a la cultura tanto en los “Estándares Nacionales para el Aprendizaje de Lenguas Extranjeras" en Estados Unidos, como en el Marco Común Europeo de Referencia.

Para Kumaravadivelu es de vital importancia desarrollar en los estudiantes la conciencia global cultural. Explica las causas de los estereotipos culturales y subraya la necesidad de erradicarlos en esta época de globalización. Al hablar sobre el multiculturalismo, aporta una visión crítica sobre este, menciona las limitaciones que se encuentran en los materiales didácticos (textos, videos, grabaciones) y señala la dificultad que representa para el maestro cumplir el objetivo de "enseñar qué decir y qué no decir en determinada situación social. 
Comenta, asimismo, las implicaciones de pasar de la competencia comunicativa a la competencia intercultural. Subraya el hecho de que los conocimientos y las experiencias aprendidos en otros contextos culturales no sólo expanden el propio horizonte cultural sino que también clarifican y solidifican el propio. Llevan a una transformación que enriquece la propia vida y la de los que nos rodean.

Es una obra muy recomendable para todos los docentes de lenguas extranjeras, pues además de proporcionar bases teóricas muy bien fundamentadas, complementa con ejemplos y casos concretos en los que se aplican las estrategias de instrucción que propone en tareas y proyectos que son factibles de realizar en diferentes contextos. Por su estilo ameno y sus sugerencias prácticas que me han llevado a la reflexión en cada capítulo, me parece uno de los libros que más han aportado a mi desarrollo profesional como docente. 

Decires es una publicación editada en línea y de libre acceso alojada en <http://www.decires.unam.mx> del Centro de Enseñanza para Extranjeros de la UNAM. Ciudad Universitaria. El cuidado de la edición estuvo a cargo de Ariadna G. Vaca Moro.

Corrección de estilo: Sharon de la Torre Monterrubio. Diseño de interiores y formación tipográfica: Yvetthe P. Rendón Rahal.

Diseño de portada: Yvetthe P. Rendón Rahal. 